\title{
Air change efficiency of room ventilation units
}

\author{
Alo Mikola ${ }^{1, *}$, Juhan Rehand ${ }^{1}$ and Jarek Kurnitski ${ }^{1}$ \\ ${ }^{1}$ Department of Civil Engineering and Architecture, School of Engineering, Tallinn University of Technology, Ehitajate tee 5, 12616 \\ Tallinn, Estonia
}

\begin{abstract}
The purpose of this study is to investigate the air change efficiency of commonly used residential room ventilation units with tracer gas concentration decay method. Carbon dioxide was used as a tracer gas in both laboratory and field measurements. The performance of room ventilation units was compared to the conventional mixing ventilation. Therefore, the laboratory measurements were conducted with horizontal supply air jet from the overhead air diffuser on the fixed supply airflow rate with various supply air temperatures. The test results showed that nearly fully mixing ventilation was achieved. Furthermore, lower supply air temperature increased the air change efficiency. In next step, the air change efficiency of three room ventilation systems were measured in the test room. Tested systems included pairwise units, monoblock unit and ventilation radiator, which was combined with mechanical extract ventilation. The measurements were carried out both during the heating period and outside the heating period. The results confirmed that all three solutions were capable of producing fully mixed ventilation. The air change efficiency was not affected by the variation of the air flow rate. Finally, tracer gas measurements were carried out in naturally ventilated apartments and the air change efficiency of these measurements were compared with the results of rooms based ventilation units.
\end{abstract}

\section{Introduction}

Ensuring the healthy indoor climate is becoming more and more important during the process of constructing and refurbishing buildings. One of the most important components of healthy indoor climate is air quality, which can be controlled by providing sufficient air exchange rate (ACR) with the ventilation system. ACR is a quantitative value, which shows the ratio of supply and extract air flow rate to the volume of the room. The air change efficiency (ACE) has to be calculated to make sure that the air quality is equally good in all locations of the room. ACE is a value which describes how effectively fresh air is distributed in the room.

ACE can be calculated using tracer gas methods. A certain amount of tracer gas is added to the room air and the concentration alteration is examined. ACE is based on the mean age of air, which was first introduced by Sandberg in 1981 [1]. The calculation methods for the mean age of air using tracer gas methods are described in detail in international standard ISO16000-8 [2]. A thorough instruction for the calculation methods has been compiled by REHVA [3]. Chung and Hsu measured ventilation efficiency with different supply diffuser positions and concluded that position of the diffuser had a remarkable effect on the contaminant removal efficiency (CRE). The maximum difference of the CRE was 39\% [4]. On the other hand, Mainz et. al. studied the efficiency, including ACE of room ventilation air-handling units with regenerative and recuperative heat recovery and came to an opposite result. ACE was not affected by the position of the airhandling unit and was uniformly high - the mean value was around $60 \%$. ACE value for fully mixed ventilation is 50\% [5]. Rojas, Pfluger and Feist studied ACE in a flat with cascade ventilation. The supply air was provided to the bedrooms, which were connected to the living-room through a corridor. The ACE of the livingroom was low, between $30 \%$ and $40 \%$ with that solution [6]. Mikola, Kõiv and Rehand measured the ACE of mixed ventilation and concluded that lower supply air temperature resulted in higher ACE value [7].

\section{Methods}

\subsection{Description of measuring methods}

The main purpose of the study is to evaluate the performance of different ventilation strategies in different environments. Thus, both laboratory and field tests were conducted. Laboratory tests were conducted in the Mektory ventilation laboratory and nearly zero energy (nZEB) test building in Tallinn University of Technology (TalTech). Field measurements were carried out in two flats with natural ventilation in Tallinn. The measurements in the Mektory ventilation laboratory and nZEB test building were carried out both during the heating period and outside the heating period.

Concentration decay method was applied and $\mathrm{CO}_{2}$ was used as a tracer gas. The advantages of $\mathrm{CO}_{2}$ include easy measuring process and low risk on health. A

* Corresponding author: alo.mikola@taltech.ee 
relatively high concentration in the outdoor air can be considered as a disadvantage. The natural concentration of $\mathrm{CO}_{2}$ was subtracted from the test values to minimize the impact on the results. Frozen carbon dioxide, also known as "dry ice" was used as a source. It was vaporized in hot water. Room air was mixed with fan to ensure uniform concentration in the room at the beginning of the experiment. People were not present in the test room during the experiment. The concentration of $\mathrm{CO}_{2}$ in the room air was raised to $5000 \mathrm{ppm}$. The lower limit of the decay calculation was set to $1500 \mathrm{ppm}$. The calibration process of used $\mathrm{CO}_{2}$ based concentration decay method is described in detail by Mikola, Kõiv and Rehand [7]. It is shown that the correlation between the real decay curve and the theoretical exponential decay decreases at lower concentration values [7].

Firstly, ACE was measured in Mektory ventilation laboratory using perforated overhead air diffuser with horizontal supply jet. Two different supply air temperatures were tested. The achieve the ideal mixing ventilation the mixing fan which was placed in the middle of the test room and it was used to verify the used methods. The setup of the test room in Mektory lab is shown in Fig. 1 The floor area of the test room was 33 $\mathrm{m}^{2}$ and the effective volume was $90 \mathrm{~m}^{3}$. A total of ten $\mathrm{CO}_{2}$ sensors were placed in different positions in the test room, including one on the extract grille. The positions of the sensors are shown in Fig. 2. The objective was to cover the room evenly to measure air change efficiency in all areas of the room. Evikon CO2-RH-T E2228 $\mathrm{L} \mathrm{CO}_{2}$ sensors/loggers were used.

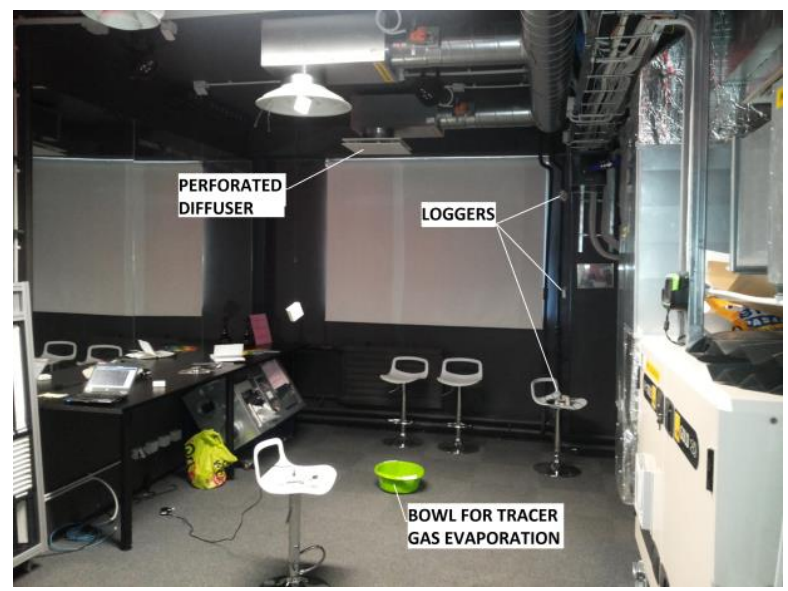

Fig. 1. The test room in Mektory ventilation laboratory.

Secondly, three different room-based ventilation systems were tested in nZEB laboratory of TalTech to determine the ACE provided by them. To to avoid the effects of the sun and other heat loads, the tests were made during stable outdoor climate conditions and cloudy periods and the curtains were in front of the windows. The area of the test rooms was $10.4 \mathrm{~m}^{2}$ and volume $31.2 \mathrm{~m}^{3}$ which is a similar size to the bedroom of a common flat in Estonia. The first examined room solution was pair-wise unit, which is a device with regenerative heat exchanger (see Fig. 3 left). The unit is equipped with only one fan, which operates cyclically both as supply and exhaust, and is located on the wall of the test room. Two units, which operated in the opposite direction, were installed in the test room. The air flow was directed upward along the wall.

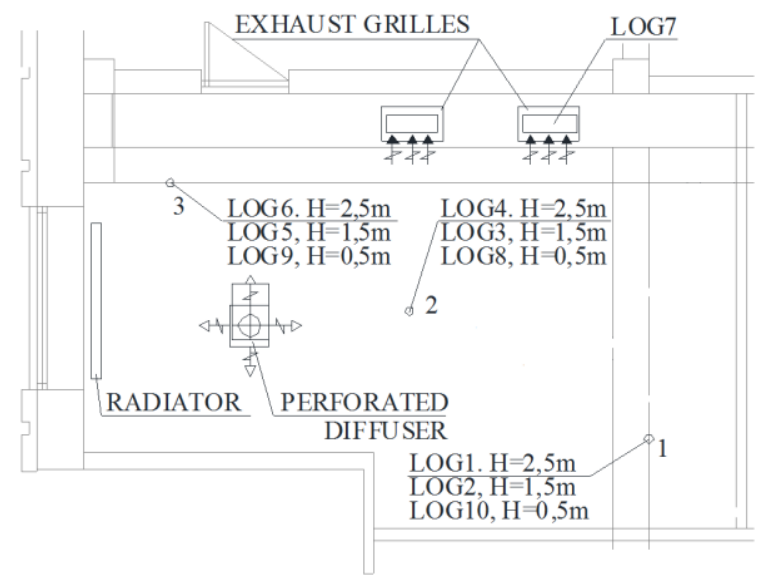

Fig. 2. The setup of $\mathrm{CO}_{2}$ sensors and air diffusers in Mektory ventilation laboratory.

The second unit was a monoblock ventilation unit equipped with recuperative heat exchanger and supply and exhaust air fans (see Fig. 3 right). The device was placed on the wall of the test room. Supply and exhaust terminals are both located on the top of the device quite close to each other.

Finally, a ventilation radiator combined with mechanical extract ventilation was tested (see Fig. 3 bottom). The radiator was located under the window and the extract valve in the ceiling in the middle of the room. The same ten $\mathrm{CO}_{2}$ sensors with a similar setup were used for concentration decay measurements. The layout of the test rooms is shown in Fig. 4.

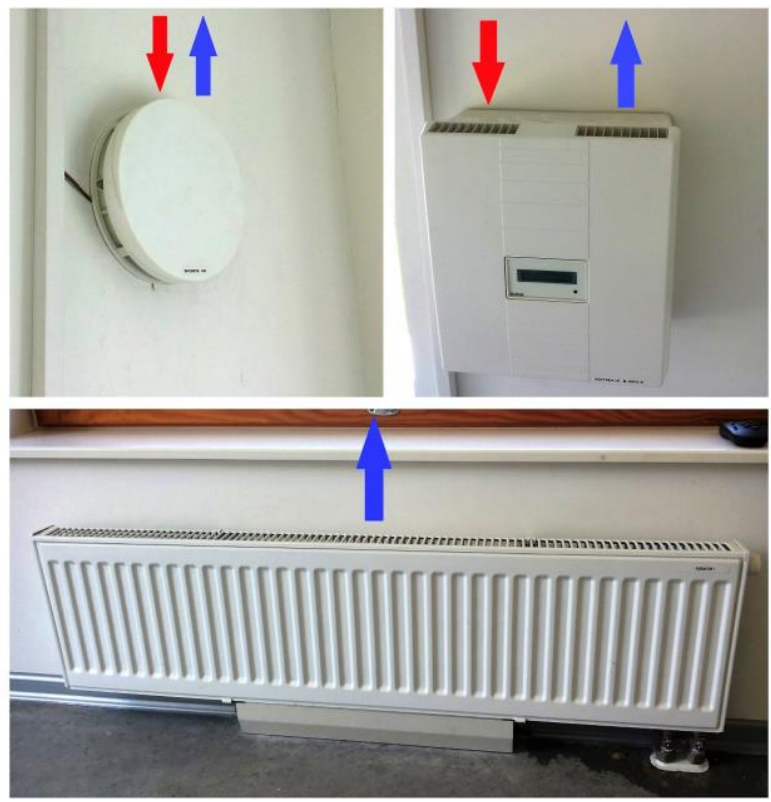

Fig. 3. Tested pair-wise, monoblock and ventilation radiator units in nearly zero energy test building. 


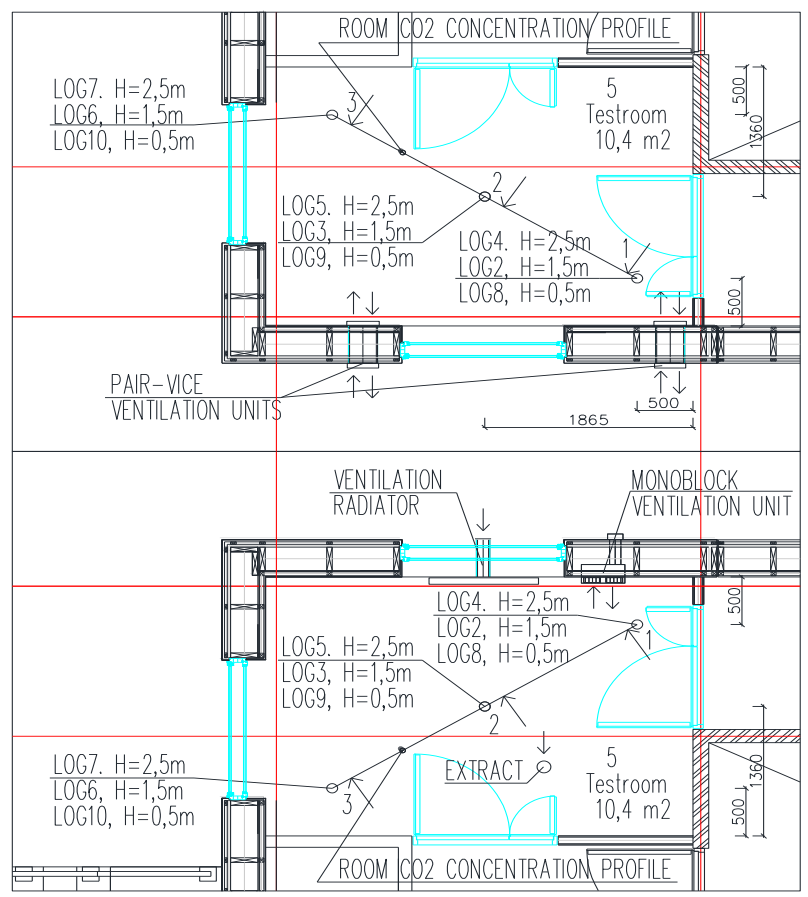

Fig. 4. The setup of $\mathrm{CO}_{2}$ sensors and air diffusers in nearly zero energy test building.

As room ventilation units have been widely used to renovate the ventilation systems of old apartment buildings, the objective was to determine whether these ventilation solutions are capable of providing fresh air to all areas of the room and therefore create a mixed air flow which is recommended solution for a common flat. All three devices were tested on two different fan speeds to verify, if the air distribution in the room was affected by the air flow rate. Fan power levels were chosen the way that the sound pressure levels in the room would be under $25 \mathrm{~dB}(\mathrm{~A})$ and $30 \mathrm{~dB}(\mathrm{~A})$, which are maximum recommended and allowed values respectively according to Estonian regulations [8], [9].

As a next step, field measurements were conducted. The air change efficiency was determined in two flats. Both of the apartments were located in a non-refurbished soviet-time building. The flats were equipped with natural ventilation with extract grilles in bathroom, WC and kitchen. No specific air intakes were installed. Such buildings represent an old not renovated building stock in Estonia. The floor areas of the flats were $43.3 \mathrm{~m}^{2}$ and $29.1 \mathrm{~m}^{2}$. The apartments were occupied by two and one persons, respectively. The floor plans of the flats are shown in Fig. 5.

Providing sufficient ventilation is especially important in the bedroom of the apartment because occupants spend the most time there. In the flats where intake and extract openings are positioned in different rooms, the air change efficiency can be significantly affected by the position of the inner doors, because pressure differences of natural ventilation are small. Therefore, tests were conducted in two different situations - with open and closed bedroom door. The doors of bathroom and toilet were closed to imitate the most common situation. $\mathrm{CO}_{2}$ sensors were placed in each room and also on each extract grille. Nominal time constant was calculated based on the average concentration decay of the extract grilles. The logging interval of the concentration was one minute. The whole apartment was considered as one air zone. Therefore, local air change index, which describes the ventilation efficiency can be calculated for each room separately.

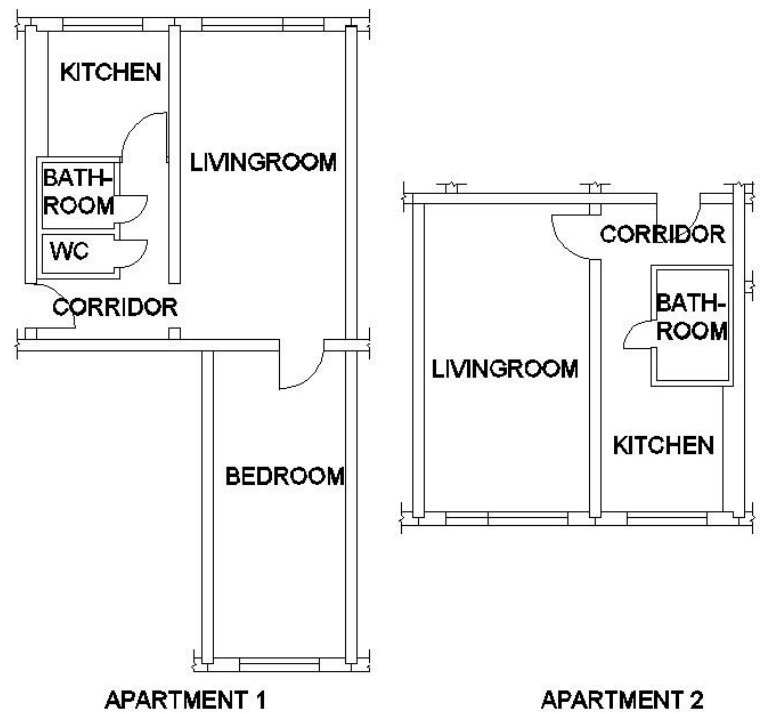

Fig. 5. The layout of the tested apartments.

\subsection{Methods for calculating the air change efficiency}

To calculate the ACE, the concept of mean age of air has to be introduced. Mean age of air is a statistical figure which is based on the age distribution of air components in a certain point and it is expressed in time units. The counting of the age starts at the moment when air enters the room. Air in certain point consists of components which have covered different distance in the room and also spent different period of time there. Local mean age of air $\tau_{\mathrm{p}}$ is the statistical average value of those components. The mean age of air $\langle\tau\rangle$ in the whole room is the average local mean age of air of all the points in the room. In case of fully mixed ventilation, $\tau_{\mathrm{p}}$ is equal in all room points. On the contrary, in case of shortcircuit flow, the local mean age of air is low in the shortcircuit zone and high in the stagnant zone. According to the definition, $\tau_{\mathrm{p}}$ in the extract air is always equal to the nominal time constant $\tau_{\mathrm{n}}$ of the room, which is the minimal possible time for the exchange of all room air [3].

$$
\tau_{n}=\frac{V}{L}
$$

where: $\tau_{\mathrm{n}}$ - nominal time constant, $\mathrm{h} ; \mathrm{V}$ - volume of the room, $\mathrm{m}^{3} ; \mathrm{L}$ - ventilation air flow rate, $\mathrm{m}^{3} / \mathrm{h}$.

The mean age of air was calculated according to the international standard ISO-16000-8 [2]. Although the standard provides methodology for the calculation of local mean age of air, it can be expanded to the whole room based on the definition shown above. To calculate the mean age of air in the room, the average concentration of all measured room points on each minute 
was plotted in logarithmic scale in relation with time. If the relation between the two values is exponential, the curve will be a straight line. The absolute value of the depression angle of the curve shows the average air change rate and the reciprocal of which is the mean age of air in the room [2].

$$
\tau=\frac{1}{\lambda}
$$

where: $\tau$ - mean age of air, $\mathrm{h} ; \lambda$ - average air change rate and depression angle of the function, $1 / \mathrm{h}$.

Air change efficiency is defined as a ratio between the shortest possible air change time and the actual air change time $\tau_{\mathrm{r}}$. It can also be described as the ratio between the shortest possible mean age of air and the actual mean age of air. The shortest possible mean age of air in the room is $\tau_{\mathrm{n}} / 2$ which occurs in case of the ideal piston flow [3].

$$
\varepsilon^{a}=\frac{\tau_{n}}{\tau_{r}} \cdot 100=\frac{\tau_{n}}{2 \cdot\langle\tau\rangle} \cdot 100
$$

where: $\varepsilon^{\mathrm{a}}$ - ACE, $\% ; \tau_{\mathrm{n}}$ - nominal time constant, $\mathrm{h} ; \tau_{\mathrm{r}}-$ actual air change time in the room, $\mathrm{h} ;\langle\tau\rangle$ - mean age of the room air, h. ACE is expressed as a percentage with the maximum value $100 \%$ which occurs during piston flow. The ACE of ideally mixed flow is $50 \%$, displacement flow between $50 \%$ and $100 \%$ and shortcircuit flow under $50 \%$ [3]. The ACE value $50 \%$ is normal for an occupied room [10].

A concept of local air change index $\varepsilon_{p}^{a}$ is defined to measure the ACE in a certain room point. It is defined as a ratio between nominal time constant and local mean age of air [3].

$$
\varepsilon_{p}^{a}=\frac{\tau_{n}}{\tau_{p}} \cdot 100
$$

where: $\varepsilon_{p}^{a}$ - local air change index in point $\mathrm{P}, \% ; \tau_{\mathrm{n}}$ nominal time constant, $\mathrm{h} ; \tau_{\mathrm{p}}$ - local mean age of air in point $\mathrm{P}, \mathrm{h}$.

\section{RESULTS AND DISCUSSION}

\subsection{Laboratory test to verify the concentration decay method}

The $\mathrm{CO}_{2}$ concentration decay method was used in Mektory ventilation laboratory to verify the presumed ACE of mixed ventilation. Firstly, the conditions of ideal mixing ventilation laboratory was tested, used the mixing fans. The results of ACE were close to ideal mixing. To analyse the influence of supply air temperature, two different supply air temperatures were tested and two separate measurements were carried out on each setting. The nominal time constant during all the tests was $0.25 \mathrm{~h}$ which calculated based on the fixed air flow rate of the ventilation unit. Fig. 6 shows that the actual $\mathrm{CO}_{2}$ concentration decay during all the tests correlated very well with the theoretical exponential decay curve that proved the accuracy of the method. The correlation was at least 0.99 in all four experiments. The steeper depression angle on Fig. 6 expresses bigger ACR and lower mean age of air in the room air. Results of mixed ventilation tests are shown in Table 1. According to the definition, the mean age of air in the extract air is equal to the nominal time constant. The maximum difference in the test results was $15 \%$.

If the supply air temperature was $16{ }^{\circ} \mathrm{C}$, the ACE values were $51.3 \%$ and $50.9 \%$ and if the supply temperature was $21{ }^{\circ} \mathrm{C}$, the ACE values were $43.1 \%$ and $46.1 \%$. This shows that the ventilation in the test room with $16{ }^{\circ} \mathrm{C}$ supply temperature can be considered fully mixed. The mixing was less efficient during tests $\mathrm{K} 3$ and $\mathrm{K} 4$, when the supply temperature was $21^{\circ}$. ACE values were $43.1 \%$ and $46.1 \%$, respectively. As both supply diffuser and extract grille were on the ceiling, the most important factor in terms of high ACE was the supply air jet throw length to reach to the floor. A visual test with smoke was also conducted. The observation verified that the supply air with lower temperature reached the floor with higher velocity. The local air change index values were constantly higher with the lower supply temperature as well. The correlation with theoretical decay was at least 0.98 for all the loggers. The local air change indexes were between $93 \%$ and $109 \%$ in tests K1 and $\mathrm{K} 2$ and between $82 \%$ and $92 \%$ in tests $\mathrm{K} 3$ and $\mathrm{K} 4$. No stagnant zone was detected based on the local measurements.

Table 1. Test results of mixed ventilation.

\begin{tabular}{|l|c|c|c|c|}
\hline Test no. & $\mathrm{K} 1$ & $\mathrm{~K} 2$ & $\mathrm{~K} 3$ & $\mathrm{~K} 4$ \\
\hline $\begin{array}{l}\text { Room and supply air } \\
\text { temperature difference }\left({ }^{\circ} \mathrm{C}\right)\end{array}$ & -6.0 & -6.9 & -1.1 & -2.2 \\
\hline Mean age of air $(\mathrm{h})$ & 0.24 & 0.25 & 0.29 & 0.27 \\
\hline Nominal time constant $(\mathrm{h})$ & 0.25 & 0.25 & 0.25 & 0.25 \\
\hline Mean age of air in extract air(h) & 0.25 & 0.25 & 0.29 & 0.28 \\
\hline Air change efficiency $(\%)$ & 51.3 & 50.9 & 43.1 & 46.1 \\
\hline
\end{tabular}

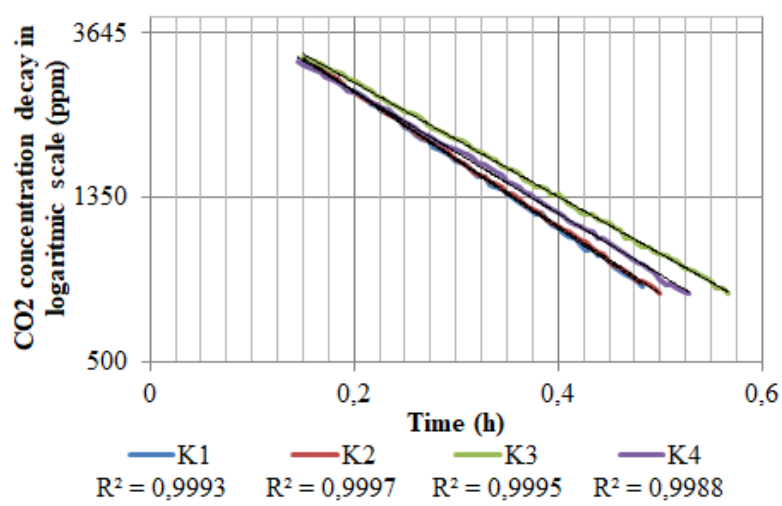

Fig. 6. Concentration decay in mixed ventilation tests.

\subsection{Laboratory test results}

Three room-based ventilation solutions were tested in nearly-zero energy test building in TalTech. The decay curve was very good correlation with theoretical curve as the correlation was at least 0.99 during all the tests in 
heating period and at least 0.98 in warm period. The results of the measurements of room-based units in heating period are shown in Table 2 and Fig. 7 and outside the heating period are shown in Table 3.

Firstly, pair-wise unit was tested in heating period and outside the heating period in different fan speeds. The room and supply air temperature differences were from $-4.8{ }^{\circ} \mathrm{C}$ to $-2.2{ }^{\circ} \mathrm{C}$. In heating period the mean age of air in tests $\mathrm{K} 5$ and $\mathrm{K} 6$ were $1.25 \mathrm{~h}$ and $1.47 \mathrm{~h}$, respectively. Despite the same fan speed, the difference was $15 \%$. It was possibly caused by the wind or the difference between supply and room temperature. If the fan speed was $50 \%$, the difference of the results was very small as the mean age of air values were $1.02 \mathrm{~h}$ and $0.99 \mathrm{~h}$.

Pair-wise units were also tested outside the heating period with fan speed $25 \%, 50 \%$ and $75 \%$. The mean age of air in tests were 1,25 h (M1), $0.96 \mathrm{~h}$ (M2), $0.58 \mathrm{~h}$ (M3) and $0.65 \mathrm{~h}$ (M4). The room and supply air temperature differences were from $-0.9{ }^{\circ} \mathrm{C}$ to $-2.1{ }^{\circ} \mathrm{C}$. The values of ACE were $46 \%-51 \%$. It can be concluded that the ACE is lower outside the heating period as the room and supply air temperature difference is lower. The temperature difference is lower outside the heating period as it is not possible to turn off the heat recovery and the heat is recovered also during the warm period.

Secondly, monoblock ventilation unit was tested. In heating period the mean age of air values were $1.54 \mathrm{~h}$ and $1.35 \mathrm{~h}$ with $30 \%$ fan power, and $1.13 \mathrm{~h}$ and $0.98 \mathrm{~h}$ with $50 \%$ fan power. As the difference of nominal time constant was in the same magnitude and the ACE values were $48 \%-50 \%$, it can be concluded that the air flow rates were different during the tests. The air flow rate was most likely affected by the pressure differences caused by wind and the difference of inside and outside temperatures.

Outside the heating period the mean age of air values were $1.1 \mathrm{~h}$ with $30 \%$ fan power and $1.13 \mathrm{~h}$ with $50 \%$ fan power. The room and supply air temperature difference were $-1.1{ }^{\circ} \mathrm{C}$ and $-1.2{ }^{\circ} \mathrm{C}$. The values of ACE were $47 \%$ and $48 \%$. In the same way, as pair-wise units, the ACE of monoblock units is lower outside heating period. The main reason is in high supply air temperature.

Thirdly, ventilation radiator was tested in combination with mechanical extract ventilation. Tests were done during heating and warm period. The air flow rates were chosen to be similar to the values of the bedroom of a common apartment. The difference between room temperature and supply air temperature were $-7.9{ }^{\circ} \mathrm{C}(\mathrm{K} 13),-5.6{ }^{\circ} \mathrm{C}(\mathrm{K} 14),-6.7{ }^{\circ} \mathrm{C}(\mathrm{K} 15)$ and $6.0{ }^{\circ} \mathrm{C}(\mathrm{K} 16)$. In heating period the $\mathrm{ACE}$ values were $49 \%-50 \%$.

In summer period two different test were made and the difference between room temperature and supply air temperature were $-8.1{ }^{\circ} \mathrm{C}(\mathrm{M} 7)$ and $-7.7{ }^{\circ} \mathrm{C}(\mathrm{M} 8)$. The airflows were similar to the heating period values. The ACE values outside the heating period were $54 \%$ in both test. The air change efficiency is higher in warm period because the heating system is turned off and the supply air is not heated.

The ACE in the test room was $48 \%-52 \%$ during all the heating period tests with all three of the units (see Table 2). As 50\% ACE value expresses ideal mixing flow, the air flow can be considered fully mixed with all three devices. It was also noted that the alteration of air flow rate did not have any impact on the ACE which means that even if the air flow rate was lower, the fresh air still reached every part of the test room. Fig. 8 shows the local air change indexes in the test room with all three room based units.

The ACE values outside the heating period were $46 \%$ - 54\% (see Table 3). In case of pair-wise and monoblock units the ACE values are higher in heating period and in case of fresh air radiators the ACE vales are higher outside the heating period. The reason for that trend is different supply air temperature. In case of pair-wise and monoblock units the supply air temperature was close to the room temperature during the warm period. At the same time in case of ventilation radiator the supply air temperature was lower.

Table 2. Test Results of room-based ventilation units in heating period.

\begin{tabular}{|c|c|c|c|c|c|c|c|c|c|c|c|c|}
\hline Ventilation Unit & \multicolumn{4}{|c|}{ Pair-wise } & \multicolumn{4}{c|}{ Monoblock } & \multicolumn{3}{c|}{ Ventilation radiator } \\
\hline Test No. & K5 & K6 & K7 & K8 & K9 & K10 & K11 & K12 & K13 & K14 & K15 & K16 \\
\hline $\begin{array}{c}\text { Fan speed (\%)/Air flow rate } \\
(1 / \mathrm{s})\end{array}$ & 25 & 25 & 50 & 50 & 30 & 30 & 50 & 50 & 7.5 & 7.5 & 10.9 & 10.7 \\
\hline $\begin{array}{c}\text { Room and supply air } \\
\left.\text { temperature difference ( }{ }^{\circ} \mathrm{C}\right)\end{array}$ & -4.8 & -2.9 & -2.2 & -2.6 & -7.2 & -10.5 & -8.7 & -10.0 & -7.9 & -5.6 & -6.7 & -6.0 \\
\hline Mean age of air (h) & 1.25 & 1.47 & 1.02 & 0.99 & 1.54 & 1.35 & 1.13 & 0.98 & 0.92 & 1.13 & 0.75 & 0.77 \\
\hline Nominal time constant (h) & 1.25 & 1.46 & 1.04 & 1.02 & 1.52 & 1.30 & 1.13 & 0.98 & 0.89 & 1.12 & 0.75 & 0.77 \\
\hline Air change efficiency (\%) & 50 & 50 & 51 & 52 & 49 & 48 & 50 & 50 & 49 & 50 & 50 & 50 \\
\hline
\end{tabular}

Table 3. Test Results of room-based ventilation units outside heating period.

\begin{tabular}{|c|c|c|c|c|c|c|c|c|}
\hline Ventilation Unit & \multicolumn{3}{|c|}{ Pair-wise } & \multicolumn{3}{c|}{ Monoblock } & \multicolumn{2}{c|}{ Ventilation radiator } \\
\hline Test No. & M1 & M2 & M3 & M4 & M5 & M6 & M7 & M8 \\
\hline Fan speed (\%)/Air flow rate (1/s) & 25 & 50 & 75 & 75 & 30 & 50 & 7.7 & 7.9 \\
\hline Room and supply air temperature difference $\left({ }^{\circ} \mathrm{C}\right)$ & -1.7 & -2.1 & -0.9 & -1.3 & -1.1 & -1.2 & -8.1 & -7.7 \\
\hline Mean age of air (h) & 1.35 & 0.93 & 0.63 & 0.69 & 1.17 & 0.86 & 1.12 & 1.09 \\
\hline Nominal time constant (h) & 1.25 & 0.96 & 0.58 & 0.65 & 1.10 & 0.82 & 1.21 & 1.19 \\
\hline Air change efficiency (\%) & 46 & 51 & 46 & 47 & 47 & 48 & 54 & 54 \\
\hline
\end{tabular}



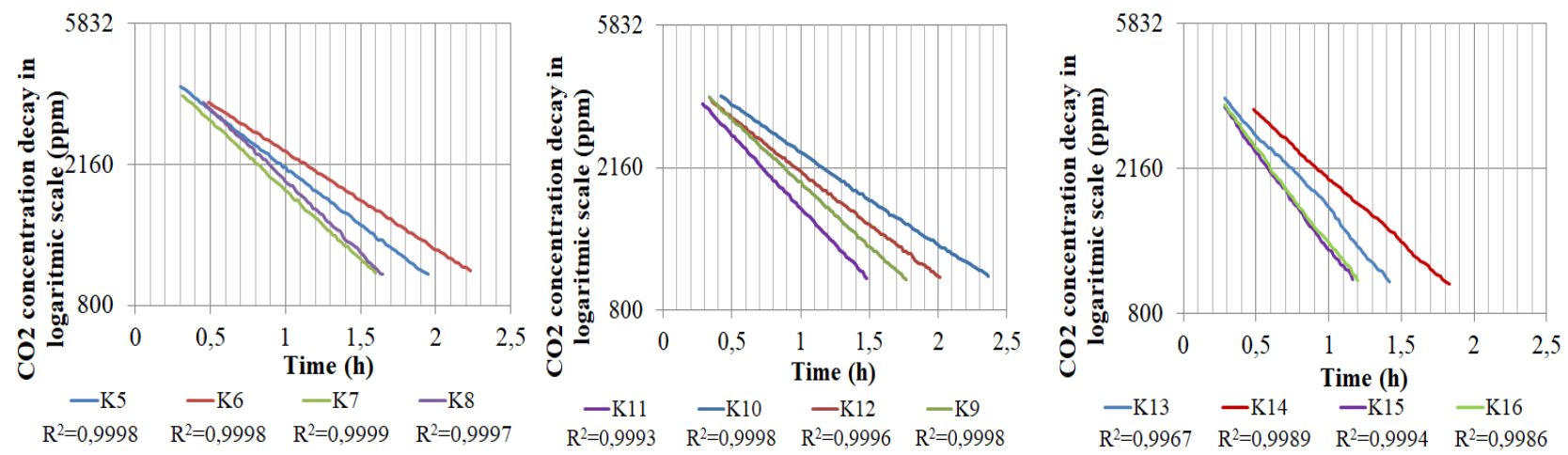

Fig. 7. $\mathrm{CO}_{2}$ concentration decay using pair-wise, monoblock and ventilation radiator units.

\subsection{Air distribution of room based ventilation units}

The air distribution of room based ventilation units is possible to analyse according to the calculated local air change indexes. The corresponding results are shown in Fig. 7 and Fig. 8. The values of local air change indexes of the pair-wise units were $93 \%-110 \%$ during the heating period. The values of ACE were $50 \%-51 \%$ and no stagnant zone was detected in the room. The local air change indexes outside the heating period were $86 \%-$ $106 \%$ in tests M1 and M2 and $86 \%-101 \%$ in tests M3 and M4.

The local air change indexes of monoblock units in winter period were $93 \%$ - $102 \%$ that proved the air change rate was uniform in the whole room. The local air change indexes outside the heating period were $91 \%$ $-101 \%$ in test M5 and 93\% - 109\% in test M6.

During the heating period, the values of air change indexes of ventilation radiator were close to $100 \%$ in all areas of the room. This proves that the supply air mixed with the room air in effective way. Outside the heating period, the local air change indexes were $100 \%-113 \%$ in test M7 and $90 \%-129 \%$ in test M7.

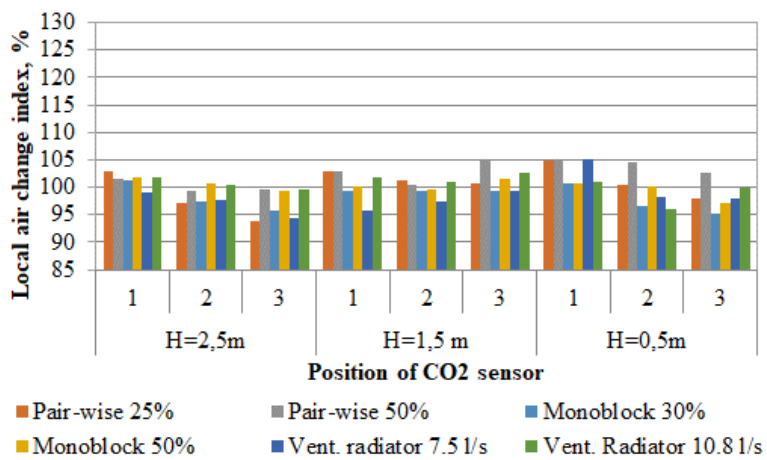

Fig. 7. Local air change indexes of room based ventilation units in heating period.

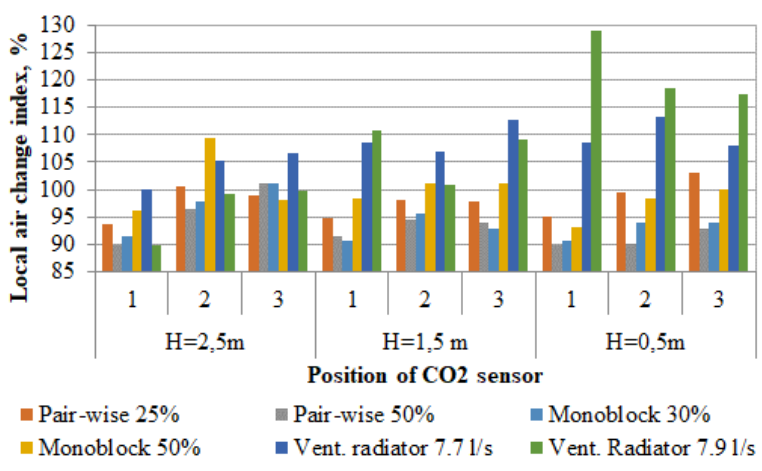

Fig. 8. Local air change indexes of room based ventilation units in warm period.

Air distribution was also analysed according to the $\mathrm{CO}_{2}$ decay patterns. The sections of the room pattern in nZEB laboratory are shown in Fig. 4 (section A-B). The air distribution patterns compiled using the linear interpolation method. The room air distribution patterns are in Fig. 9 (heating period) and Fig. 10 (warm period). To compare the different decays, the patterns demonstrated in similar $\mathrm{CO}_{2}$ levels around $2100-2800$ ppm. Analysing the patterns, the most important conclusion is that local air change indexes are highest in the middle of room. This conclusion is the same for all the studied systems in both measuring period.

In case of pair-wice system the closer corner to the unit is with higher local air change rate in warm period. At the same time, the closer and the farther corner are performing in similar way in summer. In case of monoblock units, the air pattern during both period is similar. The main difference of the air patterns of pairwice and monoblock units is related to the different supply jets. The pair-wice unit gives the supply jet across the air distributor (360 degrees). At the same time the supply airflow of monoblock unit is directed only into the upper part of the room. This aspect can also be seen in Fig. 10, where the local air change rate of monoblock unit is higher in the bottom part of the room.

In case of ventilation radiator, the air pattern in heating period is quite uniform, but at the same time the local air change rate in upper part of the room is lower than in other part of the room. The main reasons for this kind of pattern is quite cold supply air from the lower part of the room. In heating period the air is mixed by the convective air flow from the hot radiator, but the 
radiator was not turned on during the warm period. That is the main reason, why the ACE value is high and the concentration of $\mathrm{CO}_{2}$ level is higher in upper zone.
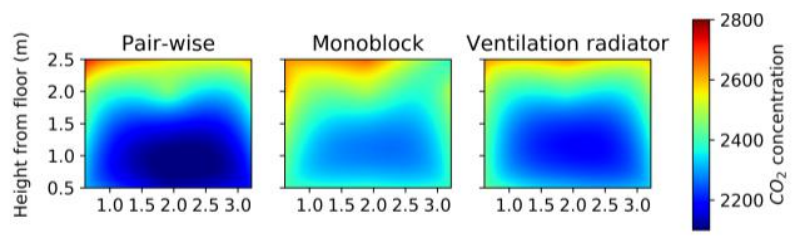

Width $(\mathrm{m})$

Fig. 9. Room air distribution of room based ventilation units in in heating period (A-B in Fig. 4).
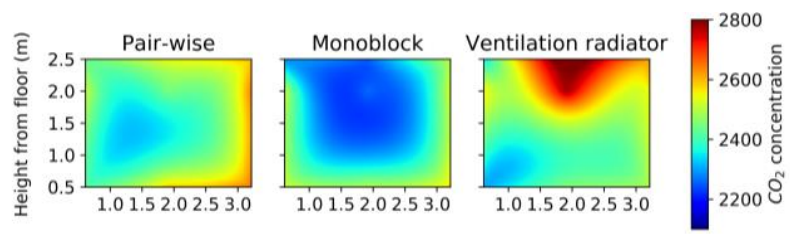

Width $(\mathrm{m})$

Fig. 10. Room air distribution of room based ventilation units in in warm period (A-B in Fig. 4).

\subsection{Field test results}

Air change efficiency measured in two naturally ventilated apartments. Tests made in the heating period and in warm period. The special focus was to determine how the position of the inner doors affects the ACE in the apartment. Fig. 11 shows the natural $\mathrm{CO}_{2}$ concentration change in the bedroom and bathroom of apartment 2 during two days. The bedroom door was closed during the first night and open during the second night. The $\mathrm{CO}_{2}$ concentration in the bedroom was 500 ppm higher than in the bathroom during the first night, while during the second night the concentrations were practically even. It proves that the $\mathrm{CO}_{2}$ generated by the occupants spread and diluted in the whole apartment, if the bedroom door was open.

The whole apartment was considered as one zone during the concentration decay tests and local air change indexes were measured in every room of the flat. The measured nominal time constants and local air change indexes are shown in Table 3. Nominal time constants were calculated based on the concentration decay in the extract grille. The local air change index was the lowest in the bedroom of the second flat when the door was closed. The value was $57 \%$ while $100 \%$ expresses fully mixed ventilation. The local air change index was $61 \%$ with same conditions in flat no. 1 . As both values were clearly under $100 \%$, it can be noted that the air flow in the apartments was not fully mixed, if the bedroom door was closed. On the contrary, if the bedroom door was open, the local air change indexes in flat no. 1 were $97 \%-101 \%$ and in flat no. $290 \%-106 \%$, which indicated that the air flow in both apartments was quite uniform.

The ACE values outside the heating period were measured only in second apartment. If the bedroom door was closed, the local air change index was $97 \%-130 \%$. If the bedroom door was closed the local air change index was only $53 \%$ in bedroom. At the same time in other rooms the index varied from $95 \%$ to $102 \%$.

Air distribution was also analysed according to the $\mathrm{CO}_{2}$ decay patterns that compiled using the linear interpolation method (see Fig. 12). $\mathrm{CO}_{2}$ patterns compiled only to flat no. 2. Room air patterns are analysed in heating period with opened bedroom door, in heating period with closed door and in warm period with opened door. We can conclude that closing the bedroom door ensures uniform $\mathrm{CO}_{2}$ concentration in room. At the same time, the local air change index of bedroom is lower than in other parts of the apartment. If the inner door was open the air distribution was not uniform and the local air change rate was higher near to the fresh air valve. The local air change index was the lowest in the upper part of the inner door. In the lower part of the door, the local air change rate was slightly higher which corresponds to the theory since the air is moving into another room from there.

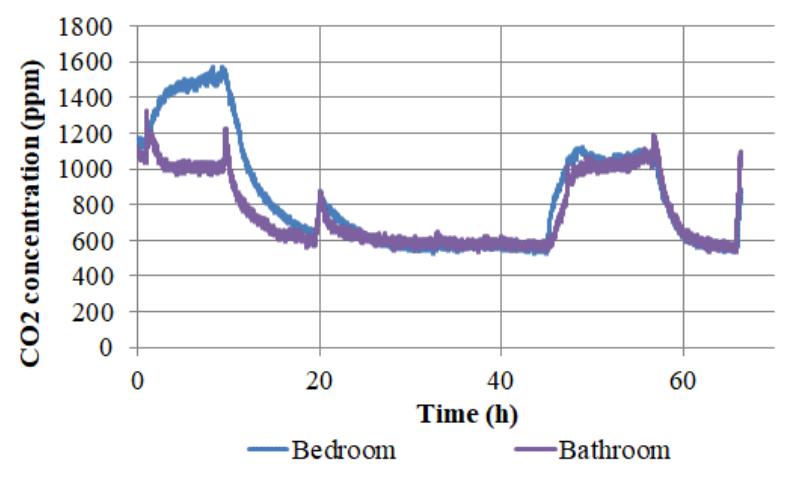

Fig. 11. Natural $\mathrm{CO}_{2}$ concentration in apartment 2 .
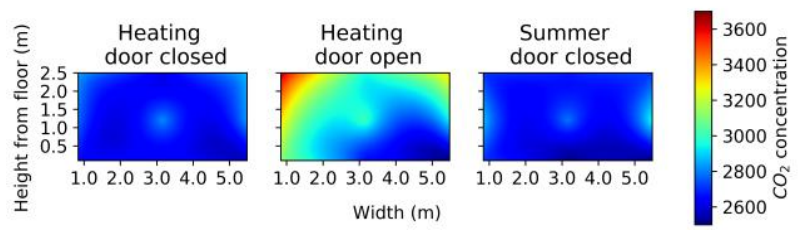

Fig. 12. Room air distribution of flat no. 2 with opened and closed door.

Table 3. Local air change indexes in apartments.

\begin{tabular}{|l|c|c|c|c|c|c|c|c|}
\hline \multirow{2}{*}{$\begin{array}{l}\text { Flat no./ } \\
\text { Period }\end{array}$} & \multirow{2}{*}{ Door position } & \multirow{2}{*}{ Nominal time constant (h) } & \multicolumn{5}{|c|}{ Local air change index (\%) } \\
\cline { 4 - 9 } & & Bedroom & $\begin{array}{c}\text { Living- } \\
\text { room }\end{array}$ & Kitchen & Bathroom & WC & Corridor \\
\hline 1/heating & Open & 4.78 & 97 & 100 & 99 & 100 & 99 & 101 \\
\hline 1/heating & Closed & 3.55 & 61 & 85 & 108 & 97 & 118 & - \\
\hline 2/heating & Open & 1.64 & 90 & - & 98 & 106 & - & 105 \\
\hline 2/heating & Closed & 2.01 & 57 & - & 94 & 100 & & 104 \\
\hline 2/summer & Open & 2.20 & 97 & - & 98 & 98 & - & 130 \\
\hline 2/summer & Closed & 2.12 & 53 & - & 102 & 98 & - & 95 \\
\hline
\end{tabular}




\section{Conclusions}

The tracer gas concentration decay method was applied to measure the air change efficiency and local air change indexes in both laboratory and field tests. After the injection and mixing of the tracer gas has stopped, the concentration of it should decrease exponentially. The results showed that the correlation with theoretical exponential decay curve was at least 0.98 in most cases which proves that the tests were conducted methodically right and that the air flow in the room was uniform.

According to the definition, the air change efficiency of the fully mixed ventilation is $50 \%$. This was achieved with perforated ceiling diffuser and $16{ }^{\circ} \mathrm{C}$ supply temperature resulting in the ACE of $51 \%$. When the supply temperature was $5{ }^{\circ} \mathrm{C}$ higher, the ACE dropped to $45 \%$, which confirmed that if the fresh air was supplied from the ceiling, it should be slightly cooler than the room temperature to ensure penetration and mixing in the whole room.

Three tested room ventilation units all created nearly fully mixed room air flows, despite the fact that the position of the supply and extract openings could have been favorable for a short-circuit flow. The ACE values were $48 \%-52 \%$ in heating period and $46 \%-54 \%$ in warm period. The alteration of the air flow rate did not have any impact on the ACE. In case of pair-wise and monoblock units the ACE values are higher in heating period and in case of fresh air radiators the ACE vales are higher outside the heating period. The reason for that trend is different supply air temperature. In case of pairwise and monoblock units the supply air temperature was close to the room temperature during the warm period. At the same time in case of fresh air radiator the supply air temperature was lower.

Air distribution was also analysed according to the $\mathrm{CO}_{2}$ decay patterns. Room air patterns compiled using the linear interpolation method. The most important conclusion is that local air change indexes are highest in the middle of room. This conclusion is the same for all the studied systems in both measuring period. According to the results of this study, these three tested solutions are well-compatible for residential ventilation that regards the aspect of air change efficiency.

The experiments in naturally ventilated apartments showed that if the ventilation scheme required transfer air between the rooms, the positions of the inner doors had a significant impact on the air change efficiency. The local air change index in the bedroom with the closed door was in worst case by $43 \%$ lower than it would have been with fully mixed air flow. The air flow was almost fully mixed in case of open bedroom doors.

Air distribution in apartment no. 1 was also analysed according to the $\mathrm{CO}_{2}$ decay patterns that compiled using the linear interpolation method. This analyse showed that the bedroom door ensures uniform $\mathrm{CO}_{2}$ concentration in room. At the same time, the local air change index of bedroom is lower than in other parts of the apartment.

\section{Acknowledgement}

This research was supported by the Estonian Centre of Excellence in Zero Energy and Resource Efficient Smart Buildings and Districts, ZEBE, grant 2014-2020.4.01.150016 funded by the European Regional Development Fund.

\section{References}

1. M. Sandberg, "What is Ventilation Efficiency?," Building and Environvent, vol. 16, no. 2, pp. 123135,1981 .

2. ISO 16000-8 "Indoor air - Part 8: Determination of local mean ages of air in buildings for characterizing ventilation conditions", International Organization for Standardization, 2007.

3. E. Mundt, H. M. Mathisen, P. V. Nielsen and A. Moser, Ventilation Effectiveness, REHVA: Federation of European Heating and Airconditioning Associations, 2004.

4. K.-C. Chung and S.-P. Hsu, "Effect of ventilation pattern on room air and contaminant distribution," Building and Environment, vol. 36, no. 9, pp. 989998, 2001.

5. H. Manz, H. Huber, A. Schälin, A. Weber, M. Ferrazzini and M. Studer, "Performance of single room ventilation units with recuperative or regenerative heat recovery," Energy and Buildings, vol. 31, no. 1, pp. 37-47, 2000.

6. G. Rojas, R. Pfluger and W. Feist, "Cascade ventilation - Air exchange efficiency in living rooms without separate supply air," Energy and Buildings, vol. 100, pp. 27-33, 2015.

7. A. Mikola, T.-A. Kõiv and J. Rehand, "The Usage of $\mathrm{CO}_{2}$ Tracer Gas Methods for Ventilation Performance Evaluation in Apartment Buildings," in Environmental Engineering 10th International Conference, Vilnius Gediminas Technical University, 2017.

8. Estonian Government regulation no. 42. "The normative noise levels in living and recreational areas, dwellings and public buildings and the methodolgy for the measurement of noise levels, Tallinn: Ministry of Social Affairs, Riigiteataja, 2002.

9. R. Simson, Performance of Room-based Ventilation Units in Renovated Apartment Building. Master's thesis, Tallinn: Tallinn University of Technology, Department of Environmental Engineering, Chair of Heating and Ventilation, 2014.

10. E. Abel and H. Voll, "Hoonete energiatarve ja sisekliima" (Energy consumption and indoor climate of buildings), Tallinn: Presshouse, 2010.

\footnotetext{
* Corresponding author: alo.mikola@taltech.ee
} 